\title{
cc) coative
}

BY-NC-SA 4.0

UMÁTICA. Revista sobre Creación y Análisis de la Imagen

\{ISSN: 2659-5354// D.L.: MA- 1628-2018\}

\section{EROTBERROCAL}

\section{El desnudo invisible}

EROtBERROCAL. The invisible nude

\section{EMILIO SCHARGORODSKY}

Film Director \& Photographer, Málaga, España.

\section{Resumen}

Este ensayo fotográfico se basa en proponer, a partir de las esculturas de Berrocal, una serie de analogías en formato fotográfico. El conjunto revela y explora una dimensión erótica del universo de Berrocal conectando las obras con prácticas vinculadas al bondage y a la dominación. Cuando revisamos la bibliografía fundamental sobre Berrocal descubrimos que la mayoría de estudios y análisis sobre su obra están, en parte, atrapados por el gran truco del artista, i.e. la excelente (obscena) capacidad de esconder secretos eróticos justo delante de nuestros ojos. La propuesta nos introduce en uno de los infinitos caminos de regreso al interior de la obra del artista eludiendo las ilusiones matemáticas y científicas del gran mago Berrocal.

PALABRAS CLAVE: Berrocal, erotismo, multiples, bondage, dominación

CÓMO CITAR ESTE TRABAJO / HOW TO CITE THIS PAPER
Artículo original Original Article

Correspondencia Correspondence

Emilio

Schargorodsky

emilioschar@ gmail.com

Financiación

Fundings

Sin financiación

Received: 14.12 .2019

Accepted: 18.04 .2020

Schargorodsky,E. (2019). ErotBerrocal. El desnudo invisible. Umática. Revista sobre Creación y Análisis de la Imagen, 2: 131-166.

https://doi.org/10.24310/Umatica.2019.vii2.10228

Umática. 2019; 2: 131-166 
Fig. 01. Miguel

Berrocal. Opus 92.

Maria de la 0 , 1962-1964.

Cortesía de la

CFundación

Escultor Berrocal

para las Artes.

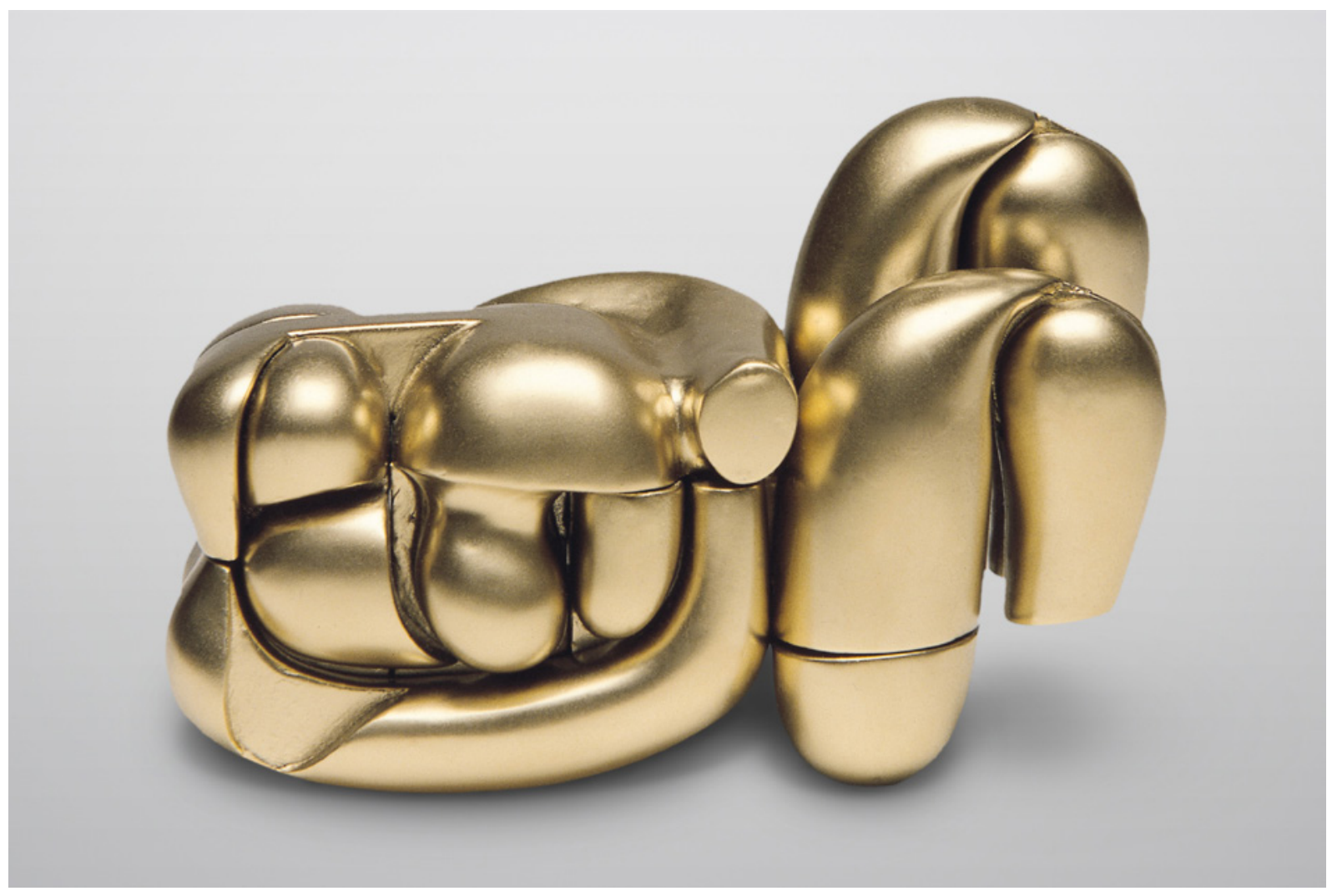

\section{Abstract}

This photographic essay is about proposing, through the sculptures of Berrocal, a series of analogies in photographic format. The set reveals and explores an erotic dimension of the universe of Berrocal connecting the works with practices used in bondage and domination. When we review the basic bibliography of Berrocal, we discover that most studies and analysis about his work are partly, trapped in the great trick of the artist, i.e. the excellent (obscene) capacity of hiding erotic secrets right before our eyes. The proposal introduces us into one of the infinite paths into the work of the artist, avoiding the mathematical and scientific illusions of the great magician that Berrocal is. 


\section{El desnudo invisible/divisible}

La magia del erotismo se encuentra en lo que se insinúa, en la sugerencia, la poesía, lo que nos incita a ver pero que no vemos... y si cruzamos esa fina línea hacia lo explícito la magia se desvanece.

ErotBerrocal es un ensayo fotográfico que propone una serie de analogías fotográficas partir de las esculturas de Berrocal. El conjunto revela y explora una dimensión del universo de Berrocal, eliminando una de las capas invisibles con la que hábilmente ha recubierto las esculturas el mago perfecto y nos muestra uno de sus secretos: la capacidad de hacer invisible lo que tenemos delante de nuestros ojos gracias a la ingeniería interna de sus artefactos.

El uso de los metales, las máscaras, los tacones y sobre todo la sofisticación del tema erótico fueron los primeros elementos que me hicieron conectar a Berrocal con el BDSM, siglas que corresponden actualmente al conjunto de prácticas eróticas entre las que se encuentran el bondage, la disciplina, la dominación, la sumisión, el sadismo y el masoquismo, y que tienen como máximo referente filosófico y literario a Donatien Alphonse François de Sade, i.e., el Marqués de Sade (1740 - 1814). Estas prácticas eróticas desarrollan de forma más profunda los caminos del deseo y las fantasías sexuales que el placer directo del acto sexual tradicional.

Mientras desarrollaba este proyecto, fui encontrando conexiones visuales que a modo de respuestas me indicaban continuar este camino y sobre todo las encontré en diferentes conversaciones con Cristina Braganza, viuda de Berrocal y Beltrán Berrocal, uno de sus hijos.

El ensayo sigue casi un orden cronológico de las obras de Berrocal y empieza por María de la O (opus 92, 1962) y finaliza con Melilla (opus 506, 2003) su última obra.

María de la $O(1962)$ es la pieza clave, y que prácticamente sintetiza el proyecto completo. Es la primera obra con la que Berrocal inicia el experimento de los múltiples haciendo 200 ejemplares y al mismo tiempo de forma explícita nos envía una señal clara desde su interior. Una de las piezas internas es un pene erecto. Hablando con Cristina de Braganza me comentó que la $\mathrm{O}$ del título de la obra era un homenaje a la novela erótica Historia de O (1954) de Pauline Reage. Esta novela narra la iniciación de una joven llamada $\mathrm{O}$ que ingresa en una fraternidad sadomasoquista donde se convierte en objeto sexual, siendo sometida voluntariamente a las prácticas de sumisión. La novela sentó las bases del erotismo moderno. He tenido la suerte de poder leer un extracto de las memorias aún inéditas de Berrocal y refiriéndose a María de la $\mathrm{O}$ escribe lo siguiente:

Quise voluntariamente violentar la indiferencia ancestral y habitual hacia este sector del arte, por lo que la aparición involuntaria de un tema erótico me sir-

$1 \quad$ Aunque suele pensarse que el título de esta pieza guarda relación con la protagonista de la conocida copla del folklore andaluz compuesta por Manuel Quiroga para Estrellita Castro en los '40, y que curiosamente remite también a una de las denominaciones que recibe la Virgen María encinta, justo ocho días antes de dar a luz.

Umática. 2019; 2: 131-166 
vió de aliciente para esperar un resultado gracias sobre todo a una cantidad de obras disponibles, no habitual, con sorpresa vi que el tema erótico era de menor atracción. La escultura se hizo famosa por su capacidad de difusión. ${ }^{2}$

Berrocal es el mago por excelencia, y hace un gran trabajo escondiendo secretos en su arte, sobre todo, los conceptos artísticos o poéticos de sus obras. Ahora ya sabemos que el tema erótico en su trabajo no son "apariciones involuntarias" pero el no hablar de la parte poética o conceptual de sus obras es otro de sus grandes trucos, que van formando un puzzle laberíntico junto a los demás elementos, como la ingeniería interna o los múltiples. Esta mezcla que enfrenta a nuestros dos cerebros -el creativo y el racional- nos va atrapando hacia el interior de la obra y como por arte de magia dejamos de ver el exterior.

El resto del ensayo sigue esta línea y aparecen elementos fetichistas que podemos apreciar a simple vista, por ejemplo, los tacones en La Totoche o sus brazos "atados", las líneas "bondage" que rodean el cuerpo de David, las máscaras de Lorelei y El Hoplita.

En las analogías de David y Romeo e Giulietta he añadido un nuevo elemento. El modelo que aparece en las fotografías es un hombre con cuerpo de mujer, podemos ver que tiene barba y sus genitales femeninos. La visibilidad de la figura "trans" pertenece a una de las preguntas sociales actuales relacionadas con las reivindicaciones de los nuevos géneros y de alguna forma sí cuestiona la obra del gran maestro respecto a los roles sexuales y los géneros en su trabajo.

La foto de la escultura de la Menina I/ he preferido dejarla de espaldas por una extraña relación: el pelo está formado por tres espirales, y hablando con Cristina de Braganza me comentó que se trataba de un símbolo utilizado por la 'Patafísica', un movimiento cultural francés relacionado con el surrealismo y que se autoproclama como "la ciencia de las soluciones imaginarias" (Jarry, 2006, pp.44), casualidades o no, este símbolo en la actualidad es un trisquel que utilizan las comunidades de BDSM.

Las fotografías de las obras dedicadas a Dalí y Picasso las he representado con unos juegos eróticos simulando las orgías de los personajes en la mazmorra. Elegí las orgías por las formas de las esculturas y por la atracción de Dalí, Picasso, Buñuel y una parte del movimiento artístico de las vanguardias hacia la liberación sexual y donde las orgías simbolizaban a veces una fantasía alcanzable y, otras veces, una fantasía tan dulcemente inconfesable como en el caso de Buñuel (Buñuel, 1982, pp. 334-335). La atracción hacia la temática erótica de los artistas españoles fuera de España como también era el caso de Berrocal, fue claramente una forma de respuesta artística colectiva. Un grito de libertad y una necesidad de expresarse frente a la represión sexual que sufría España durante la dictadura franquista

2 Berrocal, M. (2006) En Carne Viva - memorias de un escultor (inédito). Cortesía de Cristina Braganza (Fundación Escultor Berrocal para las Artes)

${ }^{3}$ Movimiento que toma como referencia el libro de Alfred Jarry, Gestas y opiniones del Doctor Faustroll, publicado en 1901

Umática. 2019; 2: 131-166 
Al margen de mis deducciones, tan objetivamente inventadas y que muchas de ellas podrían estar acuñadas por la mismísima 'Patafísica, gracias a Cristina de Braganza si pude hallar otro tipo de conexiones con el erotismo y que también forman parte del universo "Berrocaliense".

Por ejemplo que Berrocal tenía toda la colección de la revista Playboy, incluso que hay reportajes ${ }^{4}$ en los que aparecen las conejitas Playboy junto a alguna de las obras de Berrocal, opus 123 II Cofanetto (1969-75), esto es algo que Berrocal sabía y, al mismo tiempo, le inspiraba y le divertía. Otro dato relevante es que Milo Manara (1945), considerado actualmente como uno de los padres del cómic erótico, trabajaba como delineante para el estudio de Berrocal y, tal y como afirma Cristina, fue Berrocal quien lo animó a desarrollar su faceta de dibujante hacia el cómic como género y lo erótico.

El ensayo nos propone uno de los infinitos caminos de regreso hacia el interior del trabajo de Berrocal sin perdernos con las ilusiones matemáticas y científicas del gran mago.

${ }^{4}$ IL CALENDARIO PLAYBOY (1977) Fotografías de Giancarlo Baghetti, Editor de fotografía: Rosanna Amani, Playboy, 1976. Página Febrero (Febrero TN). 


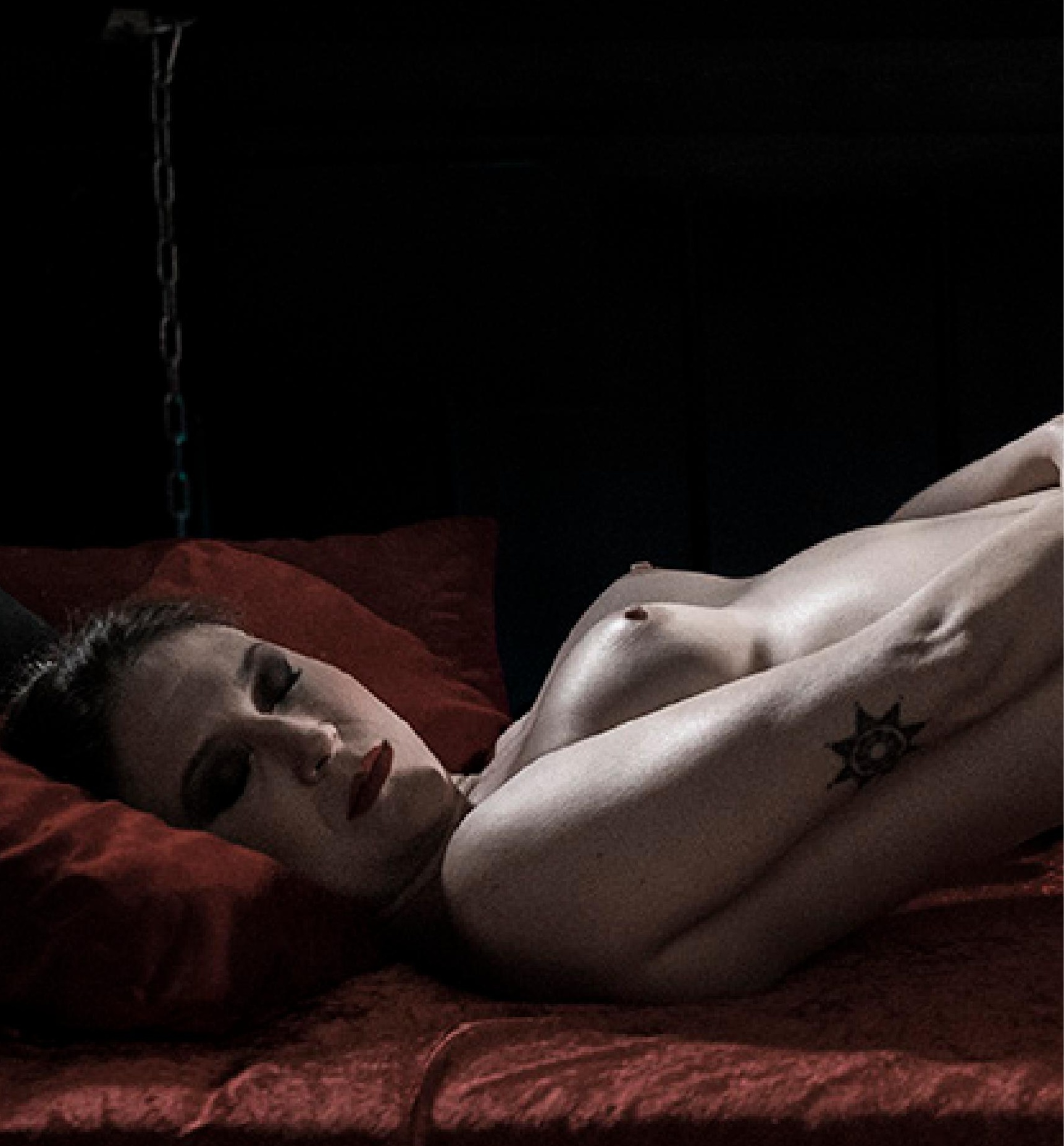




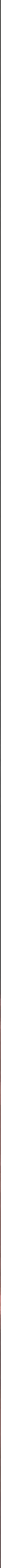




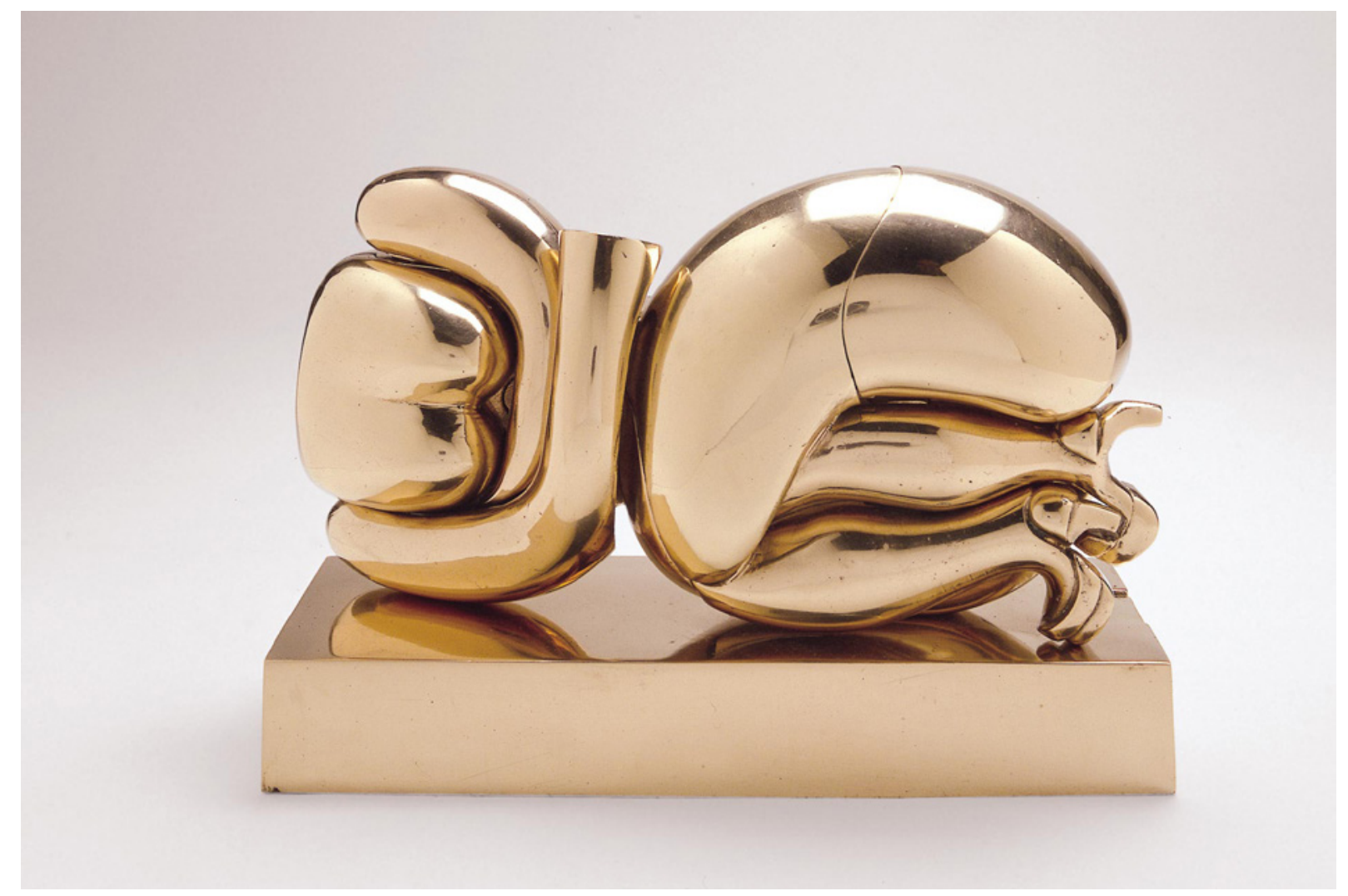

Fig. 02. Miguel

Berrocal. Opus 118.

La Totoche, 1972.

Cortesía de la

(C) Fundación

Escultor Berrocal

para las Artes. 


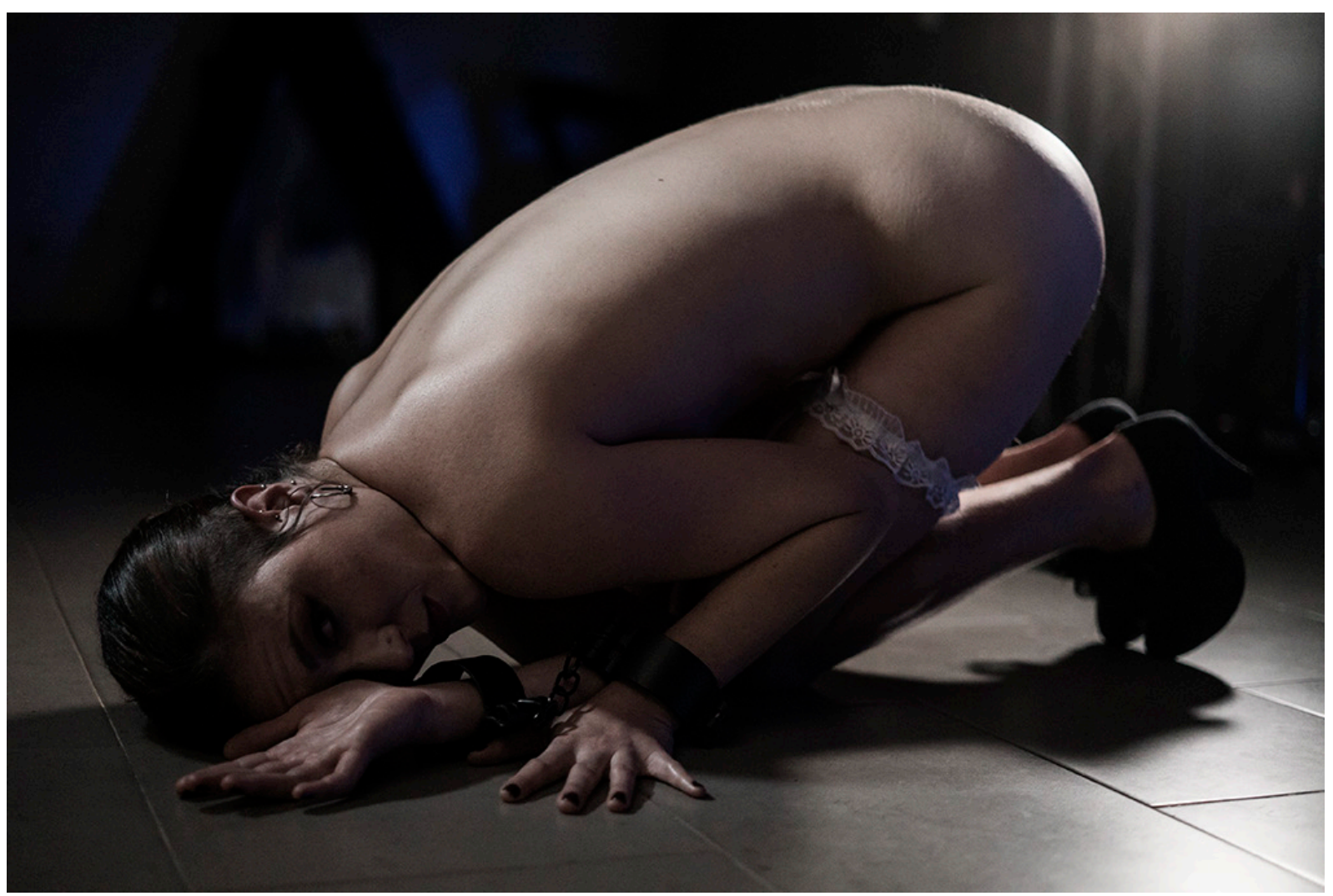




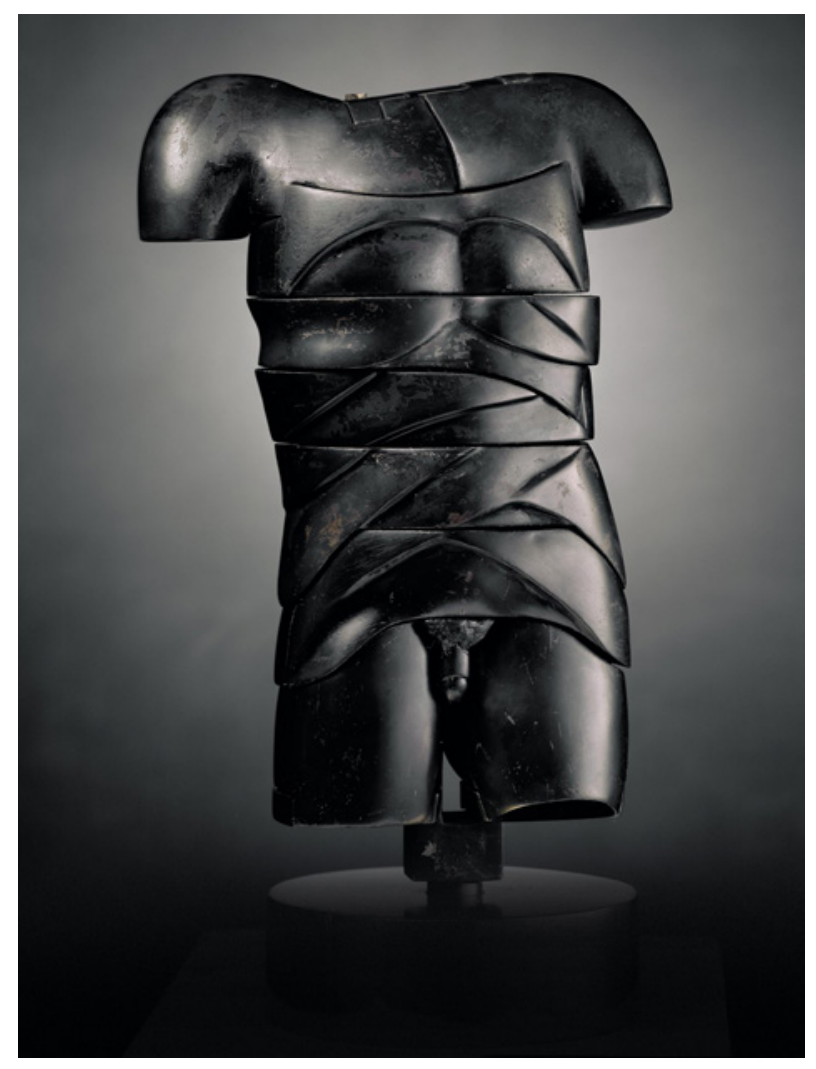

Fig. 03. Miguel Berrocal. Opus 98. David, 1966. Cortesía de la CFundación

Escultor Berrocal para las Artes. 

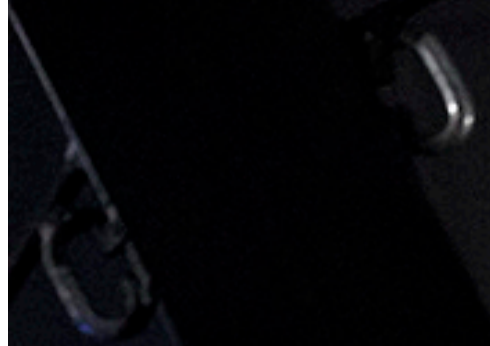


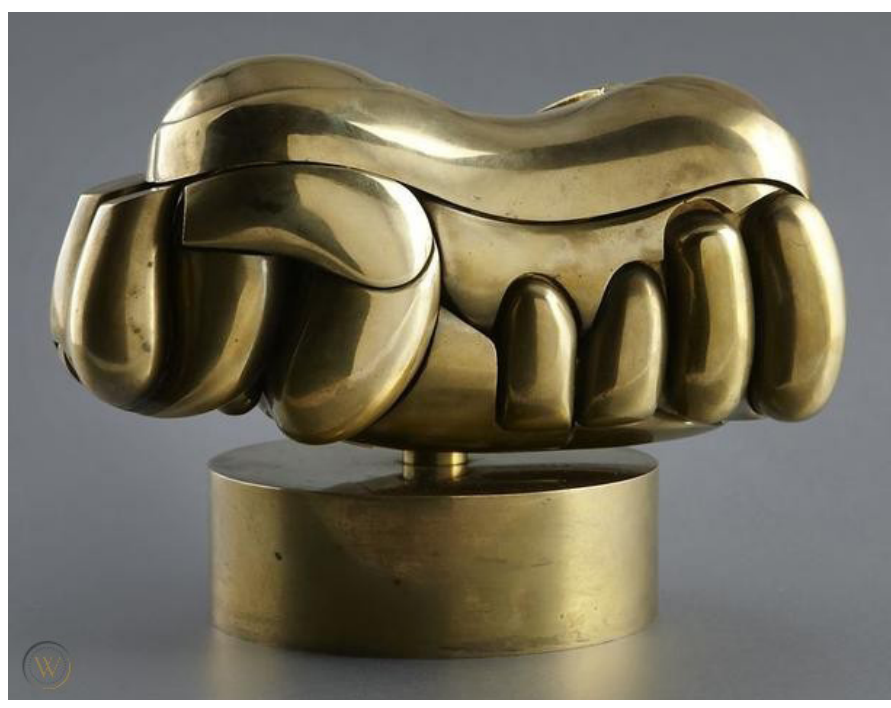

Fig. 04. Miguel Berrocal. Opus 101. Romeo e Giuletta, 1966-1967. Cortesía de la (C)Fundación Escultor Berrocal para las Artes.

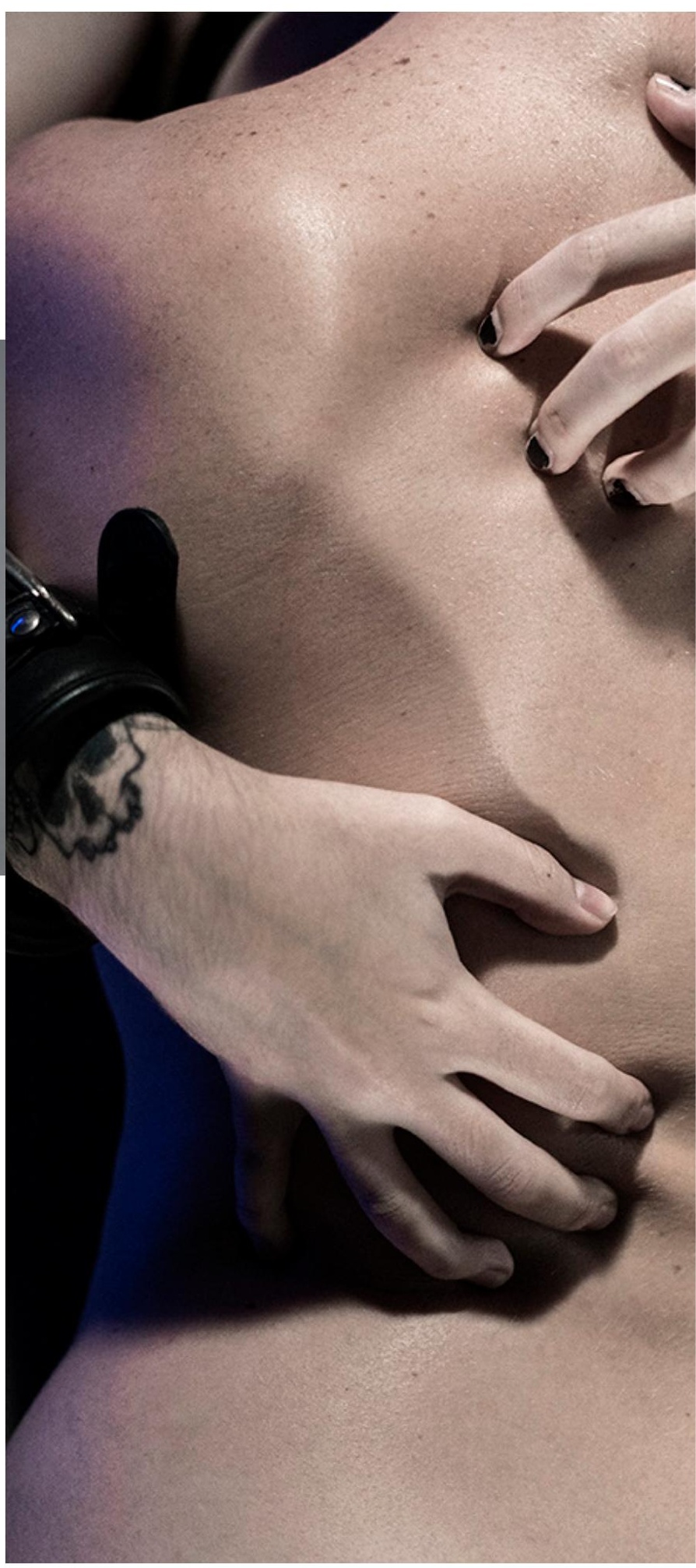




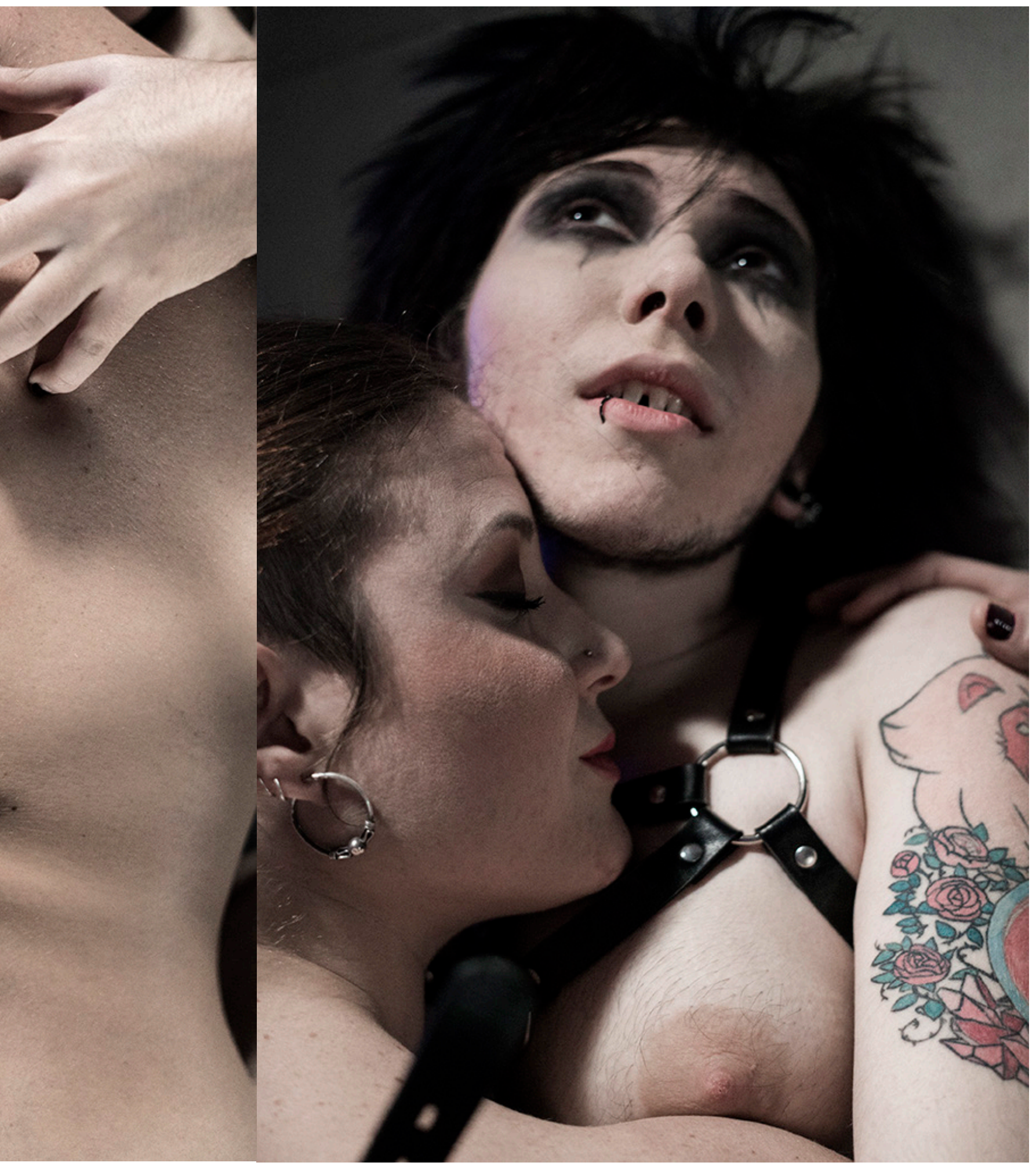




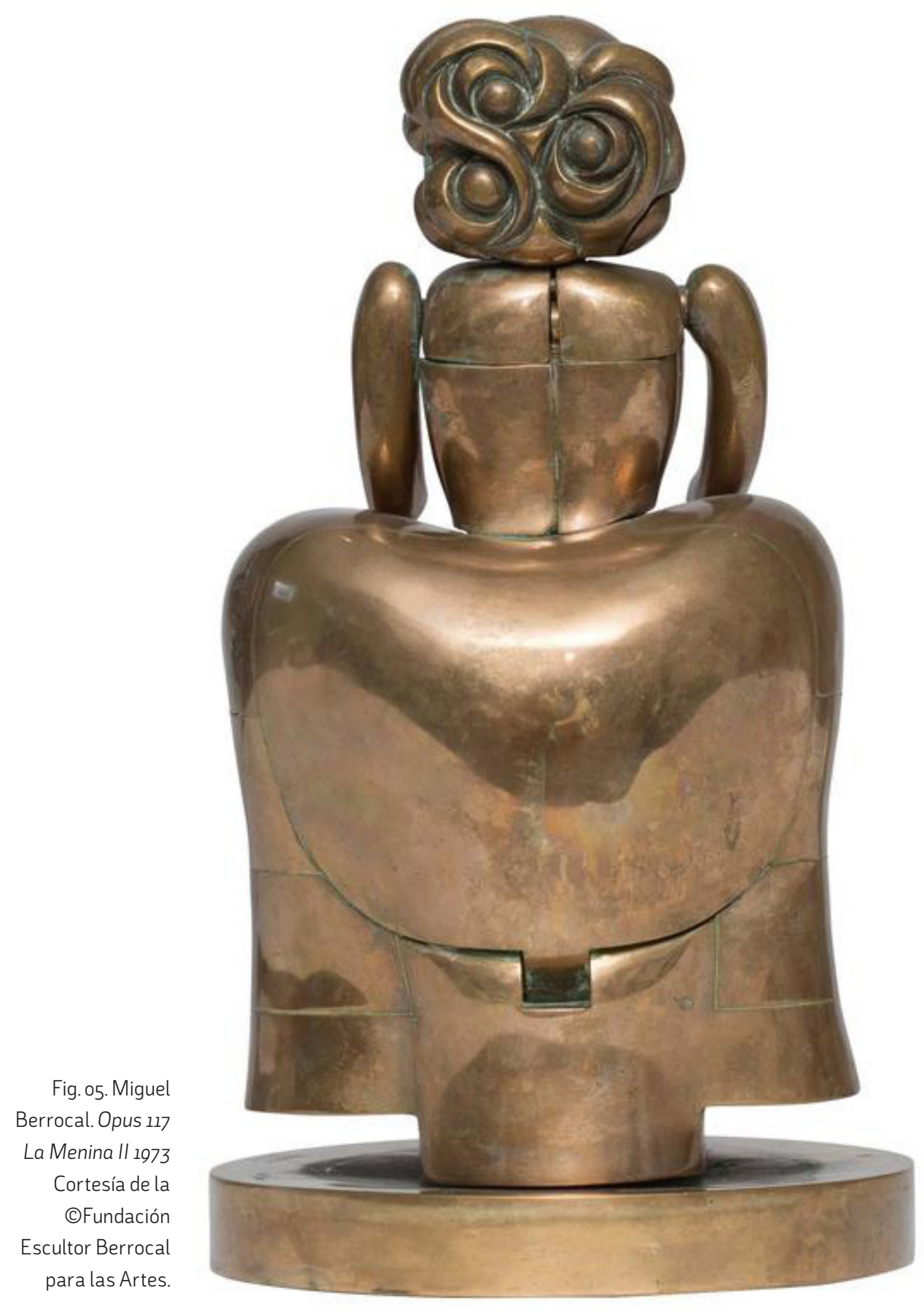



Fig. 06. Miguel Berrocal. Opus 133 Dalirium Peltro 1974 Cortesía de la (C)Fundación Escultor Berrocal para las Artes. 


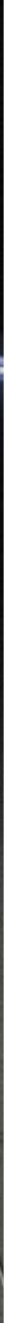




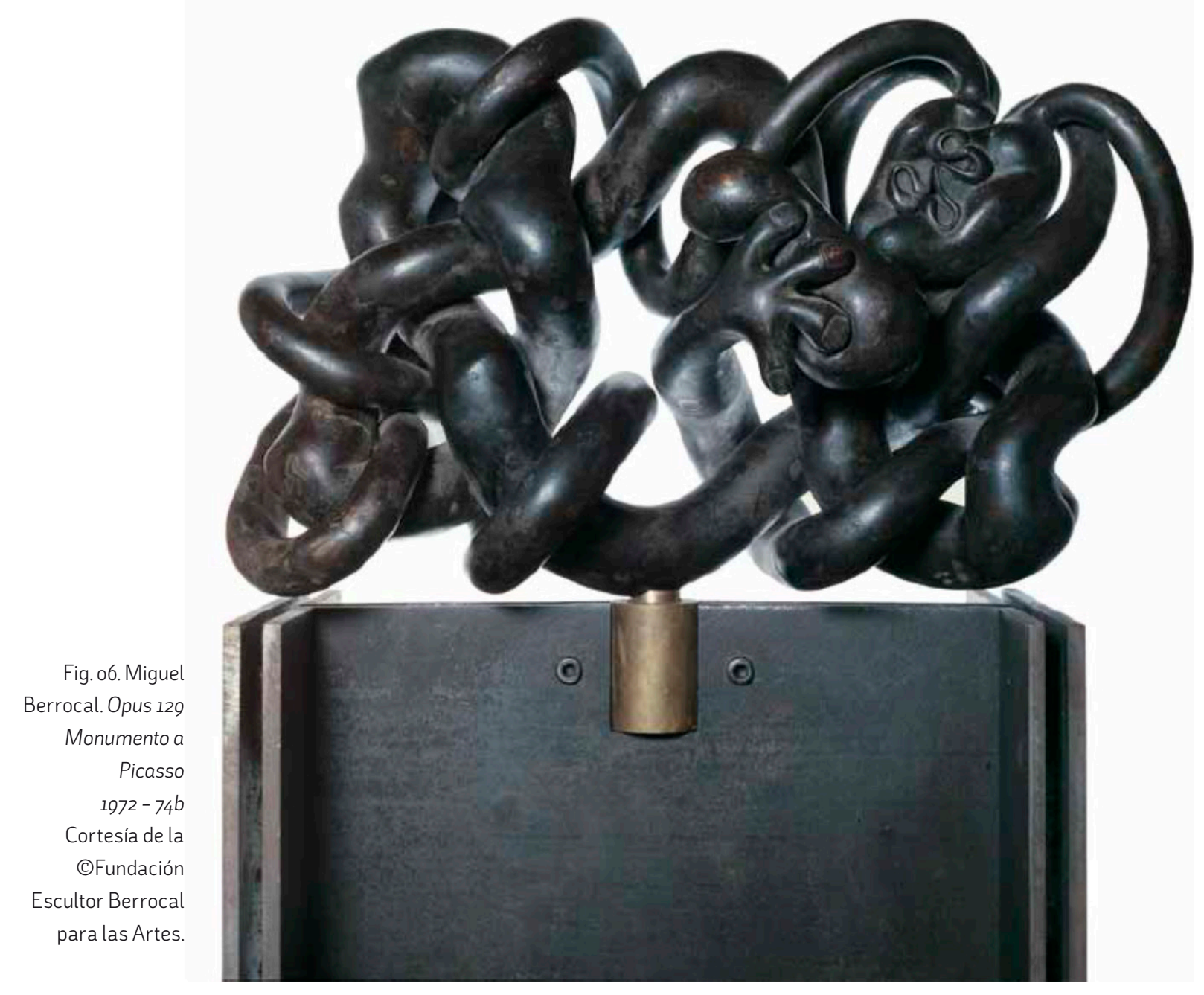




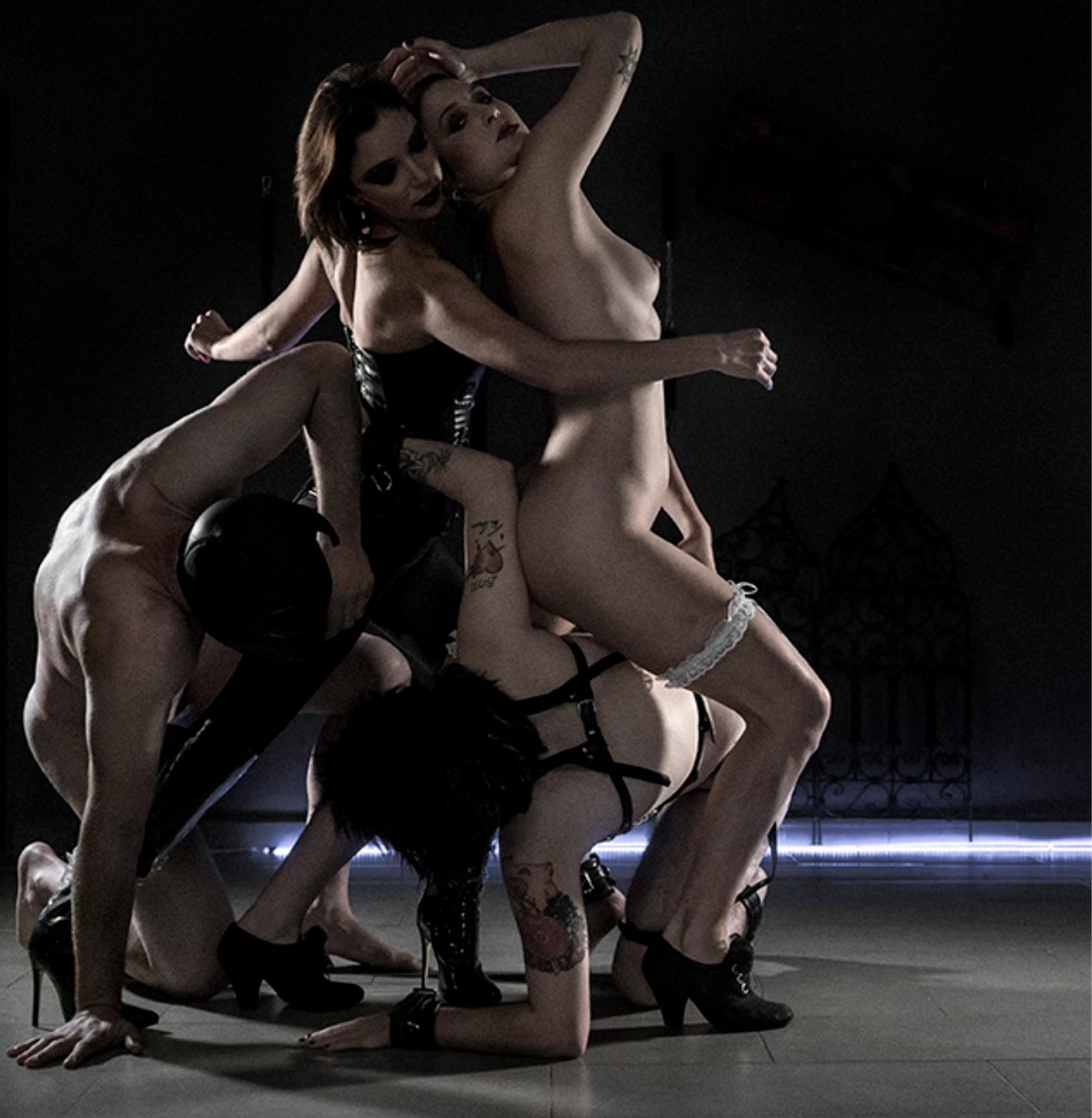


Fig. 06. Miguel Berrocal. Opus 155

Manolete

1975-77

Cortesía de la

(C)Fundación

Escultor Berrocal

para las Artes.

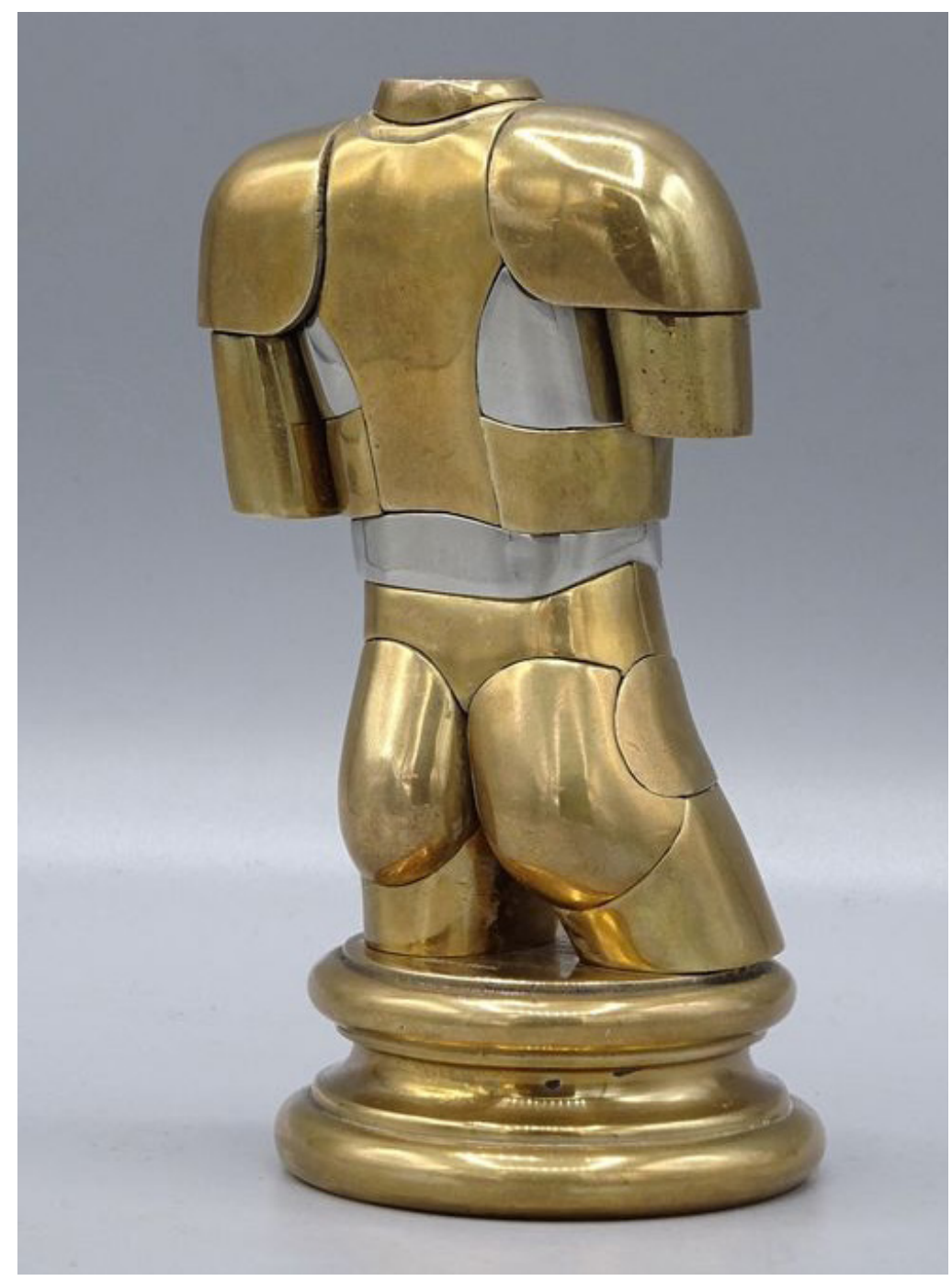




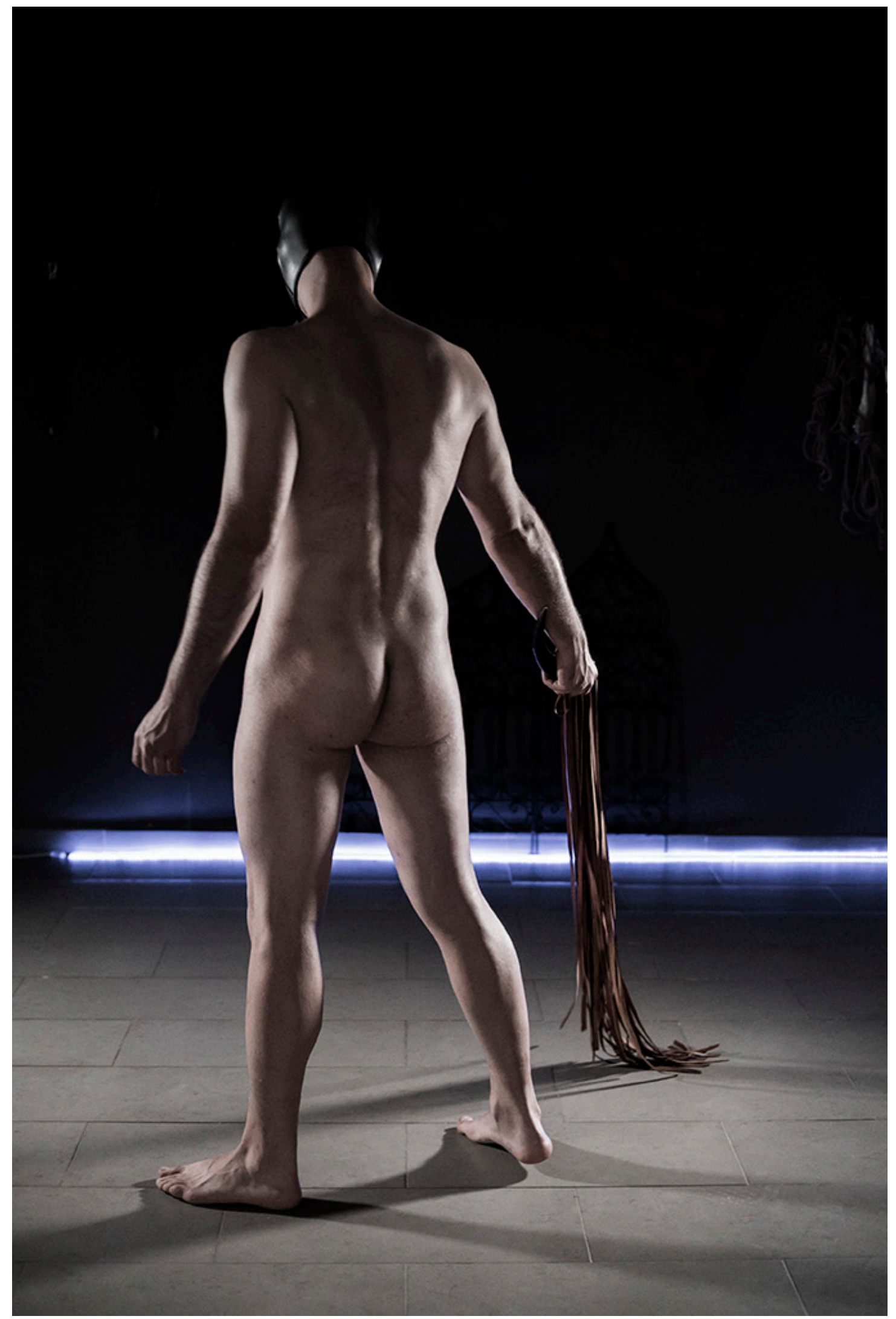


Fig. 09. Miguel Berrocal. Opus 214 Lorelei 1981 Cortesía de la (C) Fundación Escultor Berrocal para las Artes.

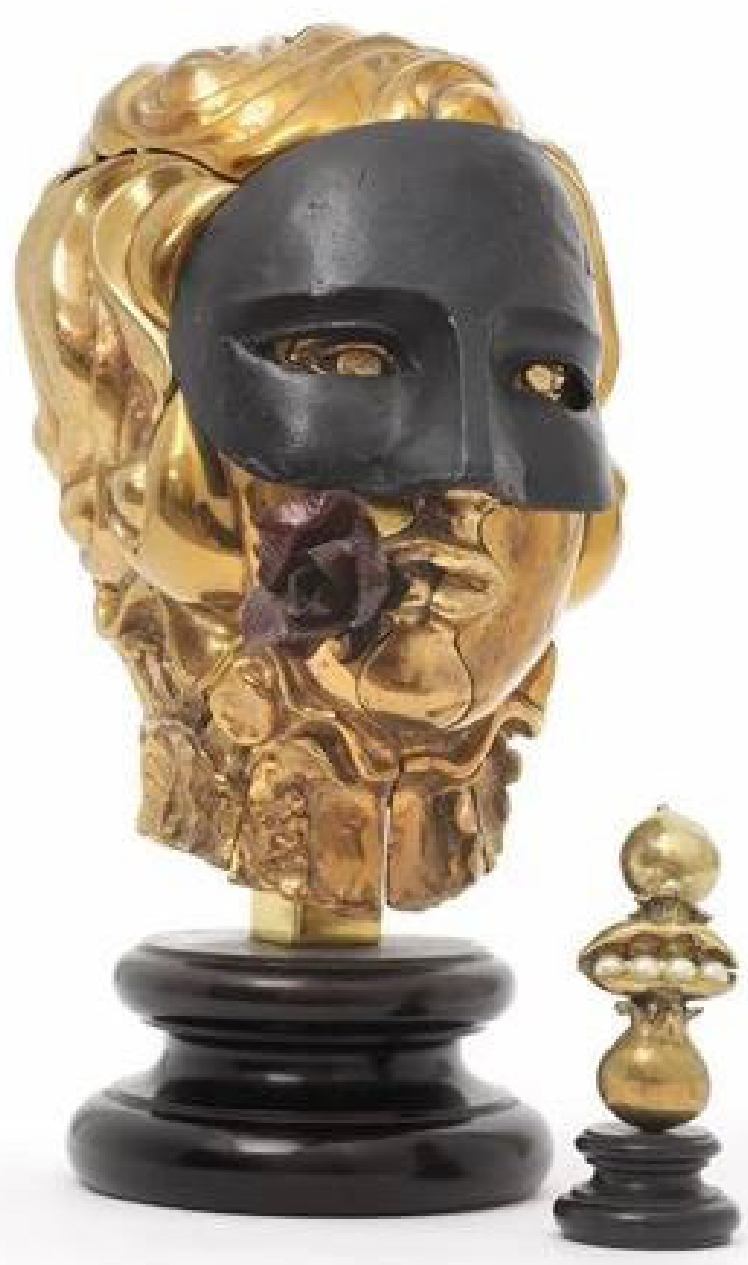




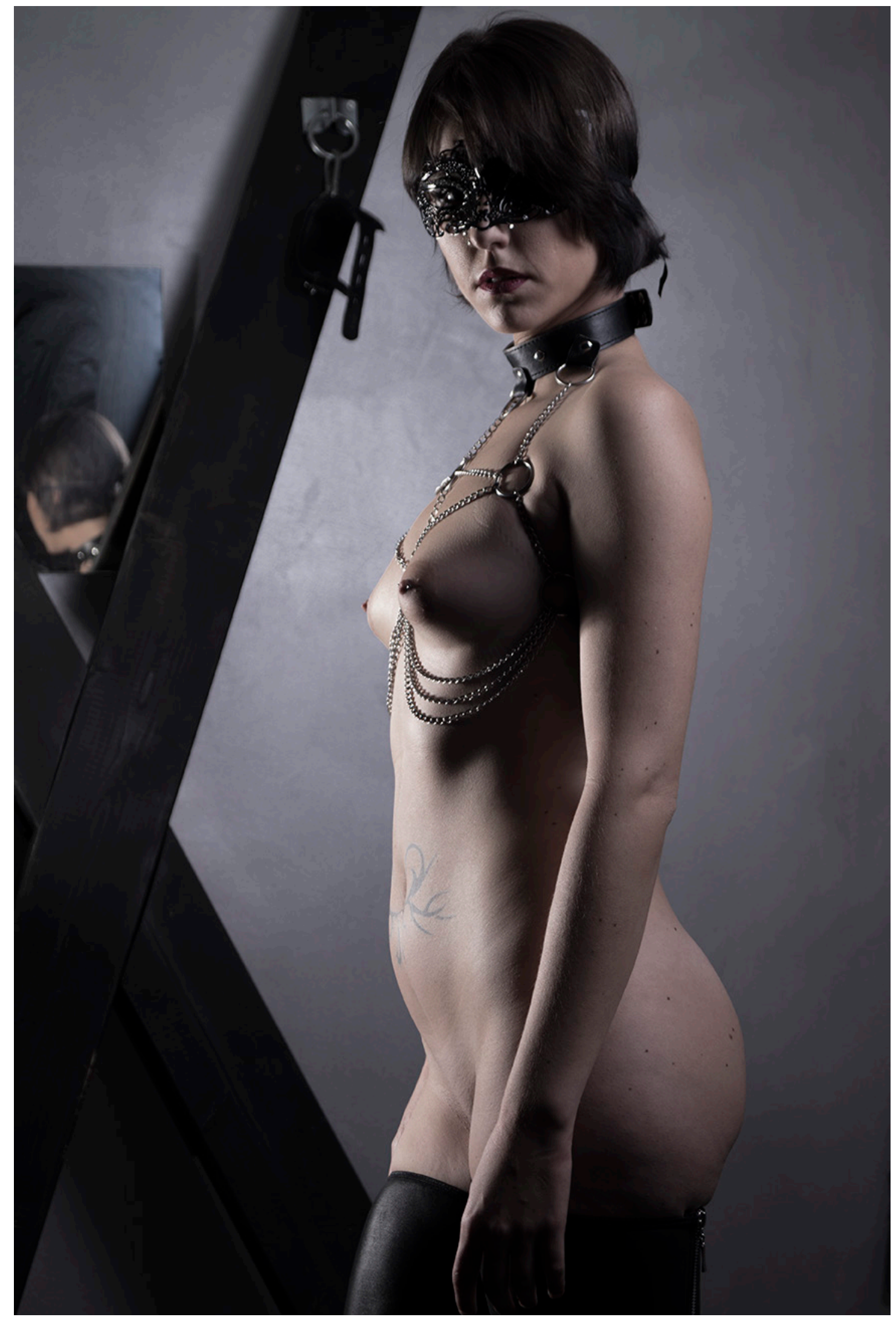


Fig. 10. Miguel Berrocal. Opus 212 Hoplita 1981- 1982 Cortesía de la CFundación Escultor Berrocal para las Artes. 


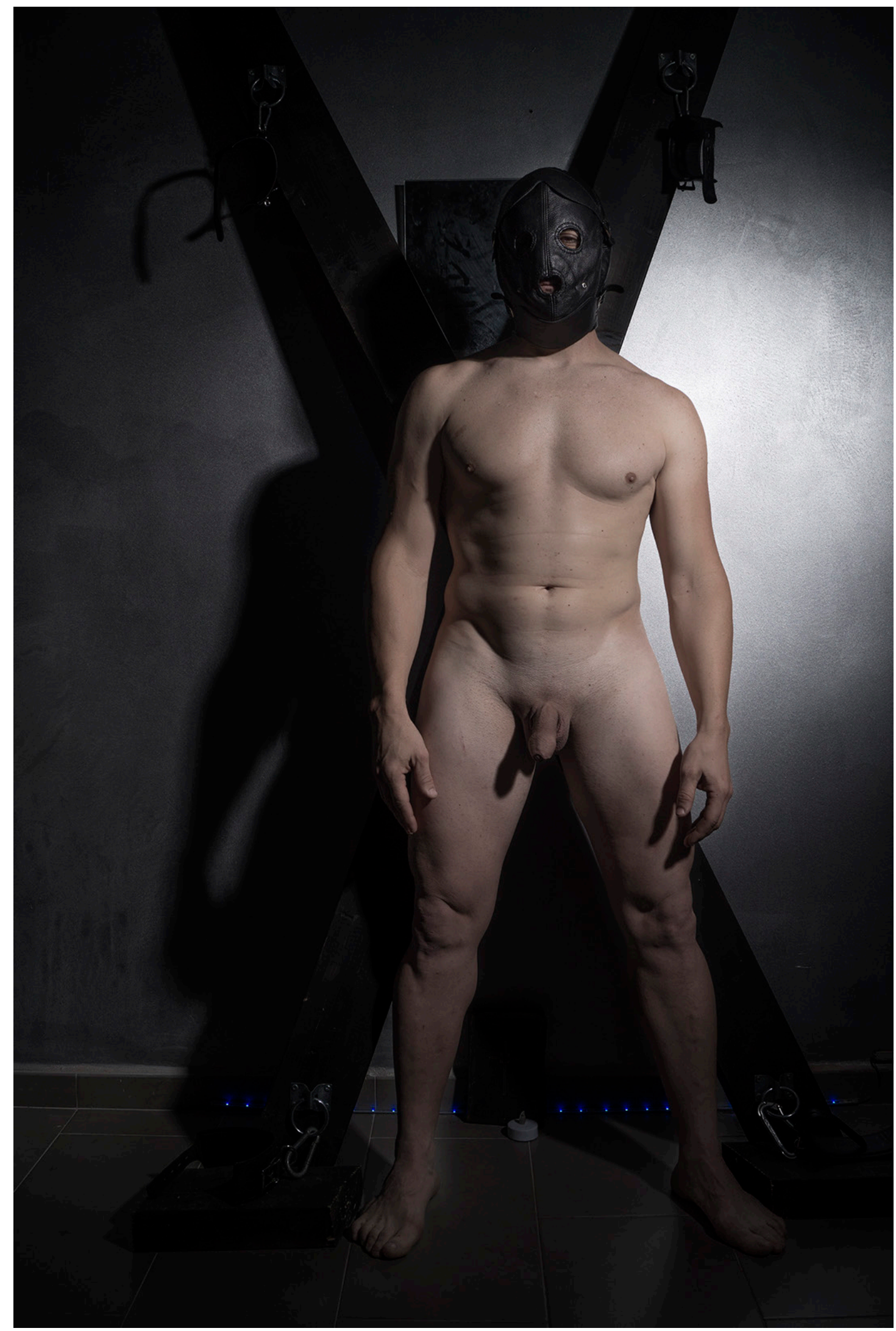




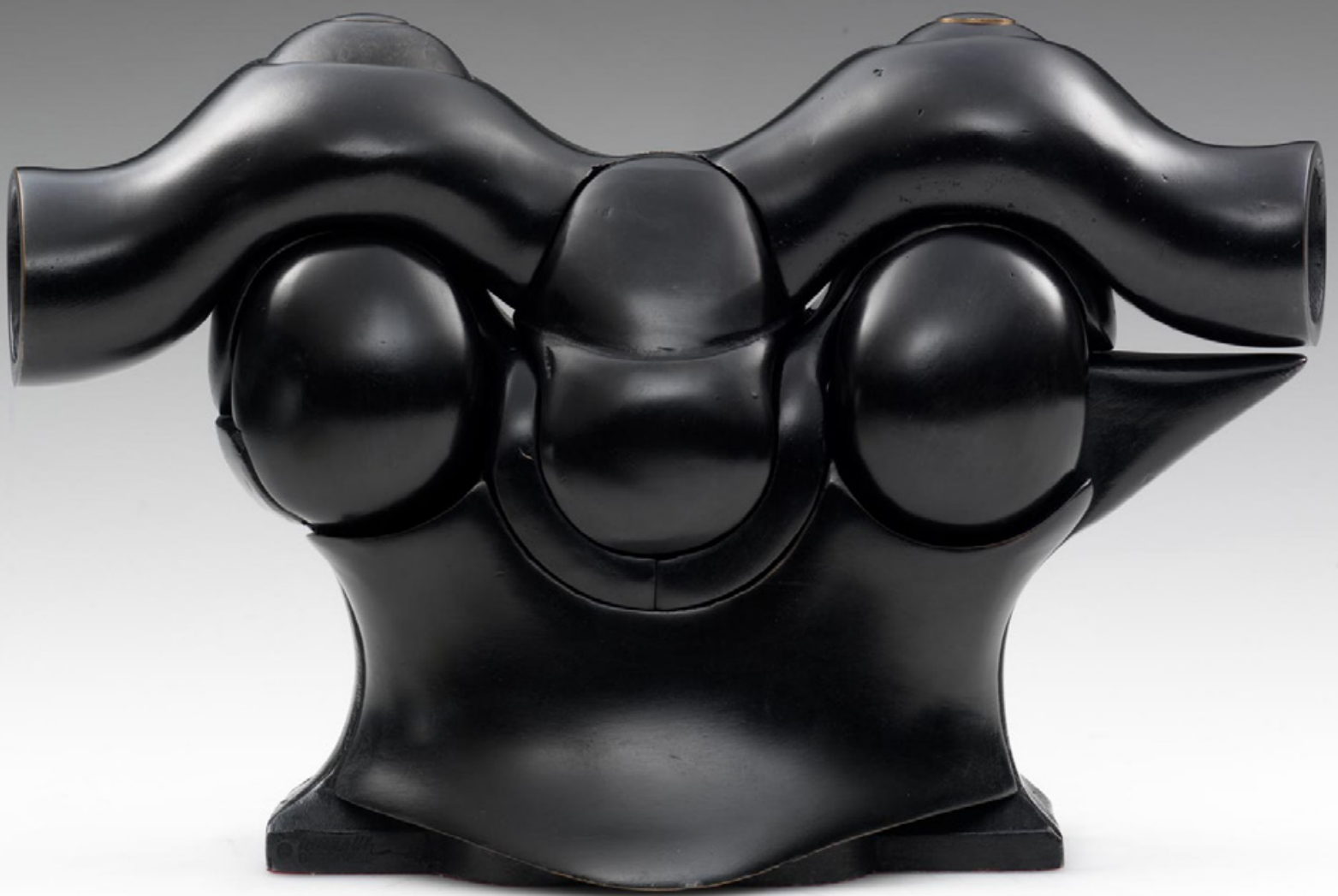

Fig. 11. Miguel

Berrocal. Opus 258

Berenguer de

Rondor /

Almogávar IX

1981-83

Cortesía de la

(C)Fundación

Escultor Berrocal

para las Artes. 


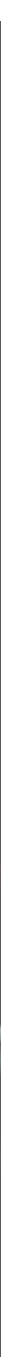




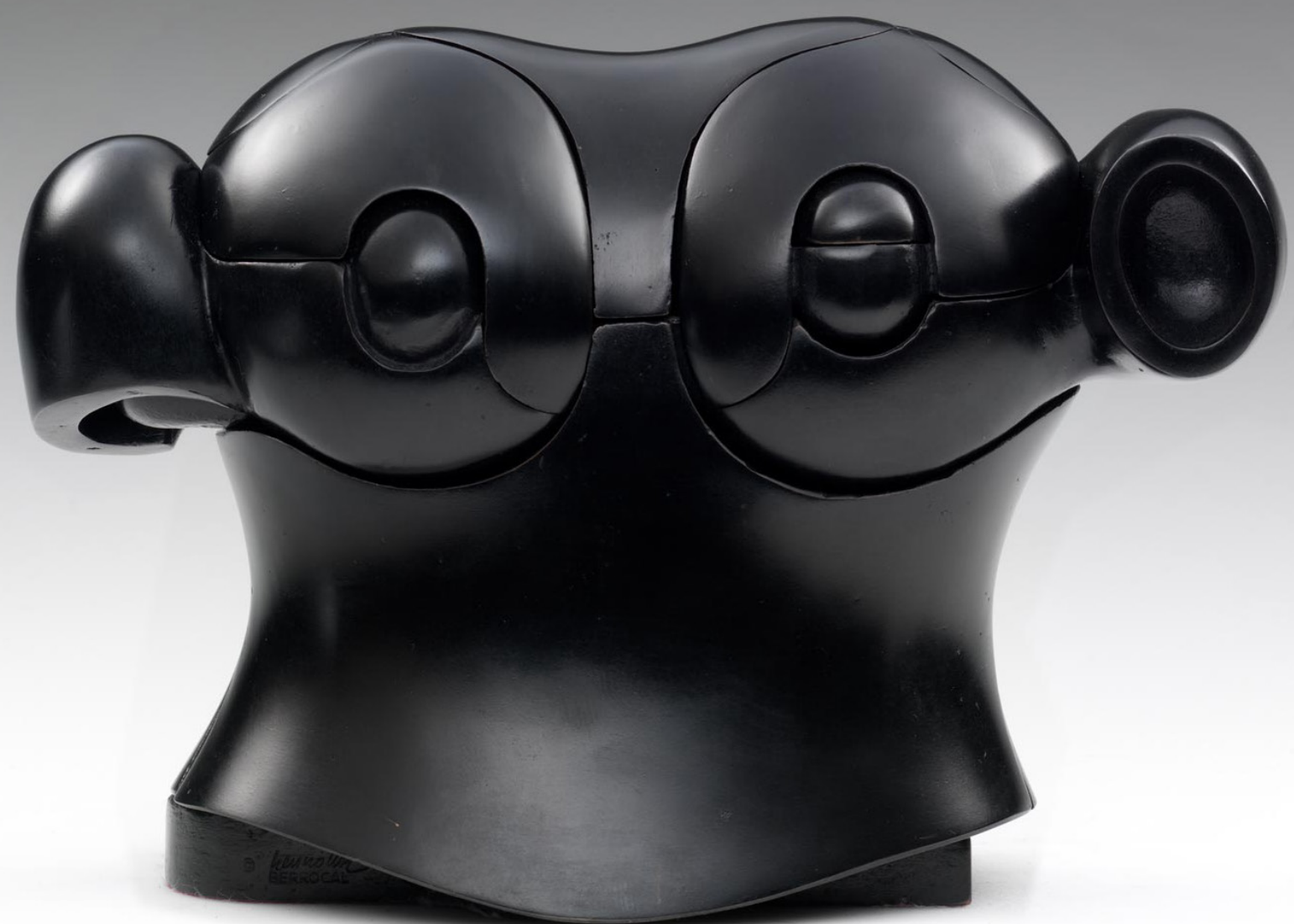

Fig. 12. Miguel

Berrocal. Opus 257

Ximenes de Arenos /

Almogávar VIII

1981-83

Cortesía de la

(C)Fundación

Escultor Berrocal

para las Artes. 


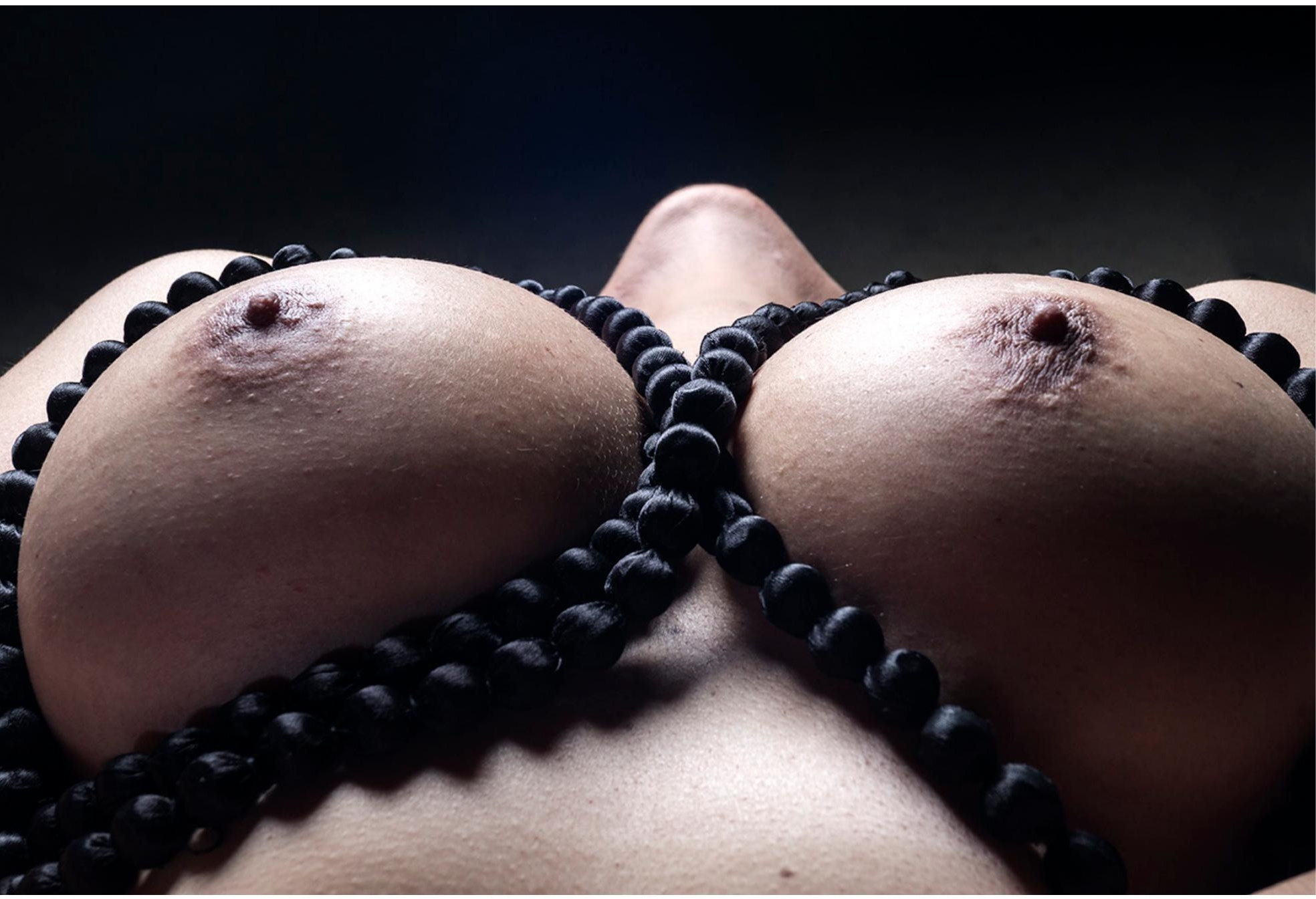




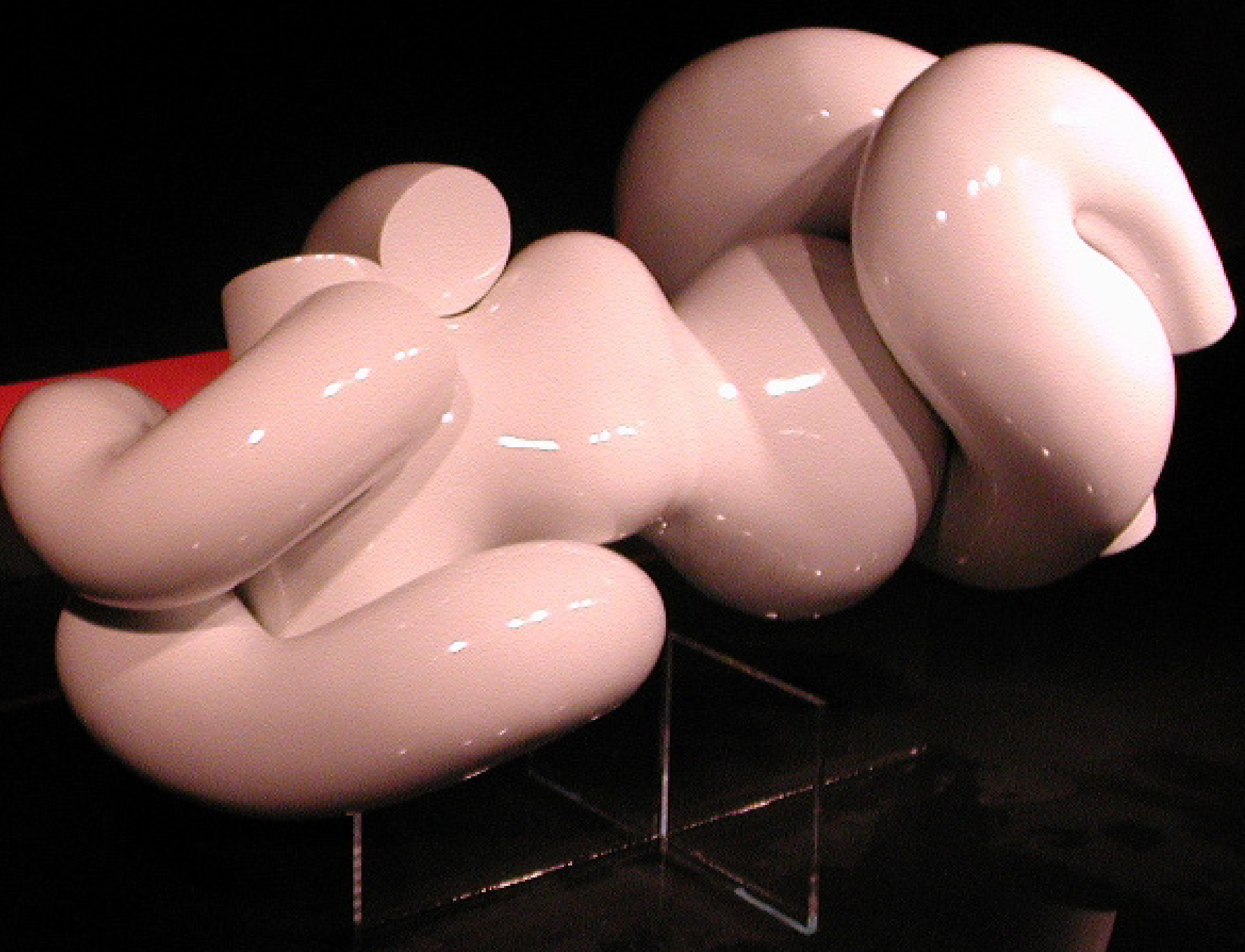

Fig. 13. Miguel

Berrocal. Opus 469

Alcudia, 1996

Valencia

Cortesía de la

(C)Fundación

Escultor Berrocal

para las Artes. 


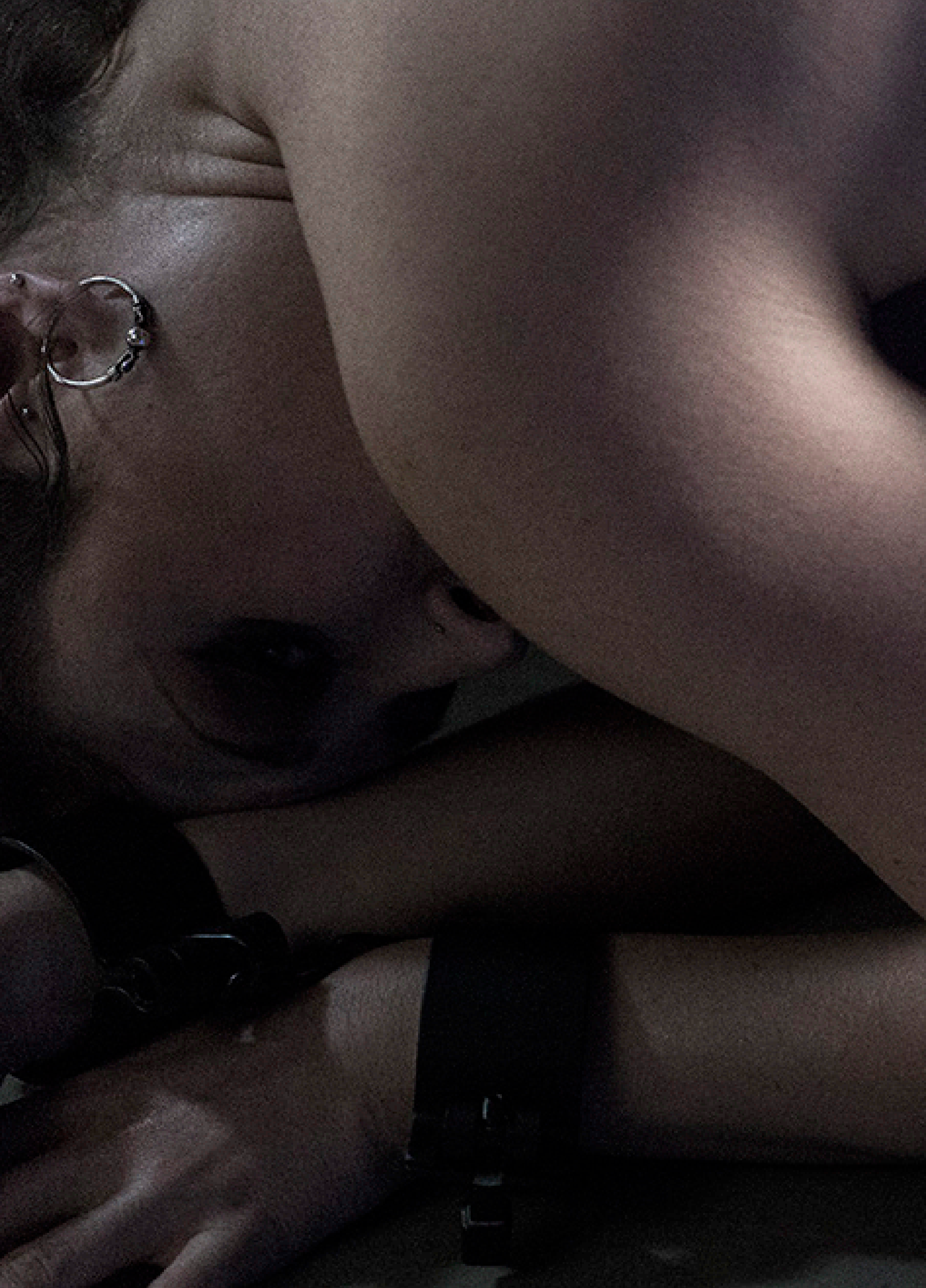




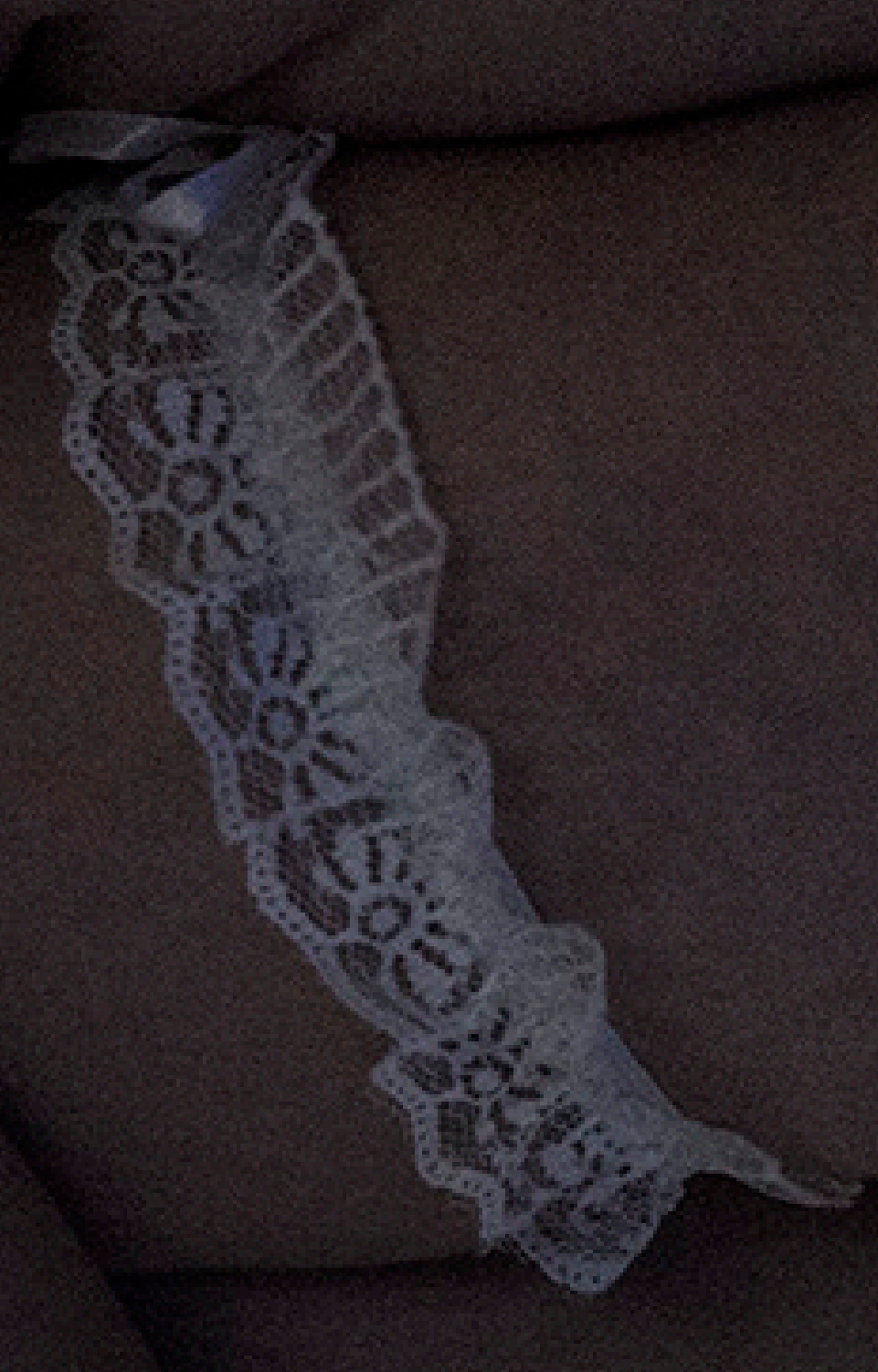




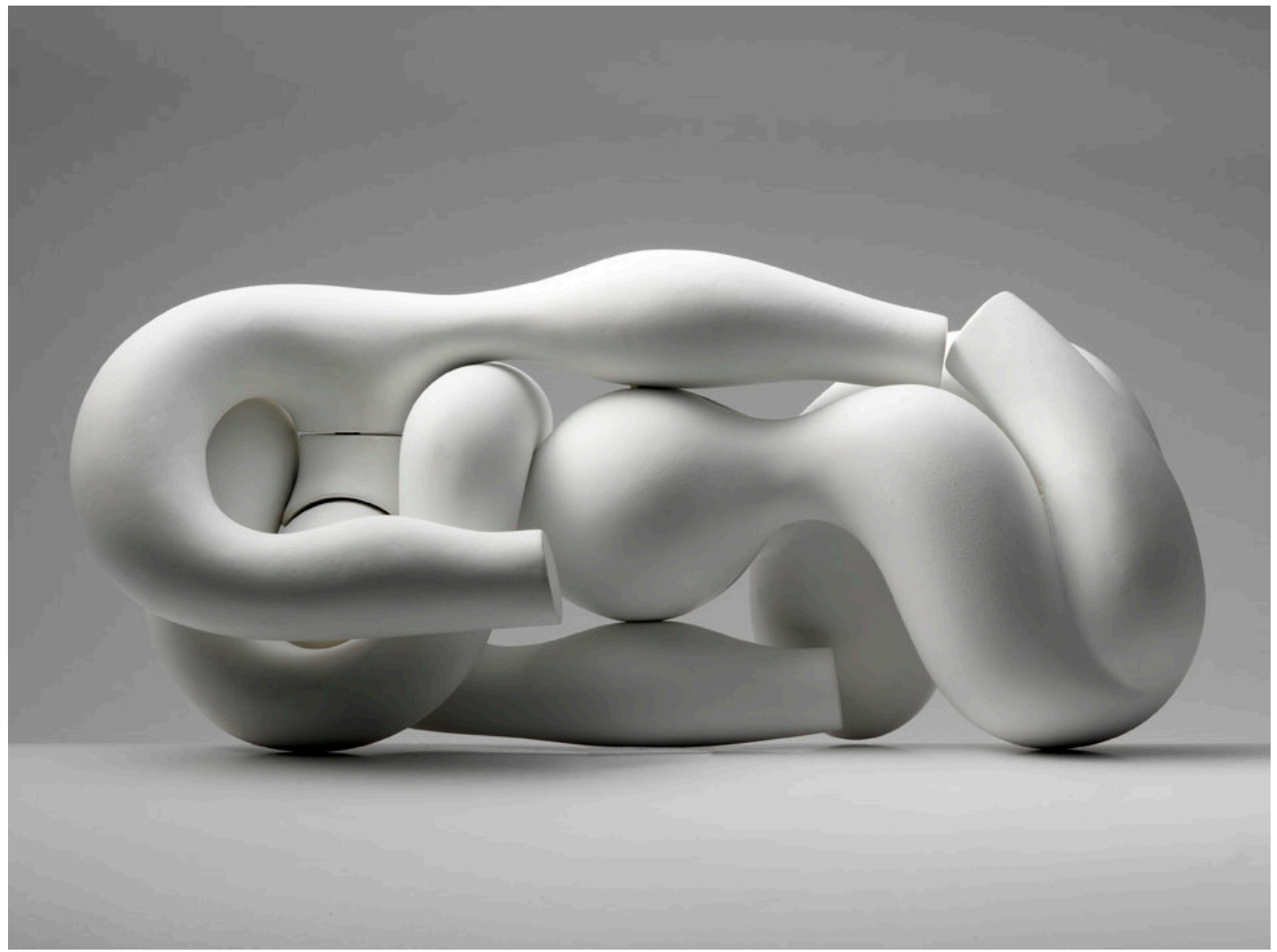

Fig. 14. Miguel

Berrocal. Opus 506

Melilla 2003

Cortesía de la (C)Fundación

Escultor Berrocal para las Artes.

\section{Conclusiones}

Lo que más me ha fascinado de este proyecto ha sido poder darme cuenta cómo los elementos internos del trabajo de Berrocal, esa parte matemática de ingeniería que permite la desmontabilidad de las piezas y la capacidad de multiplicarse, son capaces de ocultar la parte externa que tenemos justo delante de nuestros ojos.

Esta forma de esconder el erotismo y la sensualidad presenta tal grado de sofisticación que es abrumadora. Esta sofisticación de la complejidad se halla en cada uno de los elementos que toca Berrocal, tanto en su proceso creativo, como en su proceso de producción. Es así, bestial con cada elemento y en cada momento del proceso. Desde el diseño de la pieza interna más pequeña hasta la capacidad de montar unas obras con otras. Desde sus bocetos hasta los catálogos de las exposiciones. Desde lo universal hasta anclar con mil raíces su museo en su tierra natal.

Cuando revisamos la bibliografía fundamental sobre Berrocal descubrimos que la mayoría de estudios y análisis sobre su obra quedan atrapados en el gran truco del artista, la excelente capacidad para crear con el volumen, su juego con el vacío y sobre todo la ingeniería matemática de la desmontabilidad y la creación del múltiple. Berrocal es subversivo en todas direcciones, irrumpe con su sofisticación en los lugares más elegantes infiltrando elementos

Umática. 2019; 2: 131-166 
eróticos. Y provoca a los galeristas y a los museos desde el punto de vista matemático creando una obra capaz de multiplicarse como cualquier otro producto. La alteración de los géneros, sus juegos alrededor de la moda y el arte forman un gigantesco puzzle donde es fácil que te conviertas en una pieza más y que no te hayas dado ni cuenta.

La "Capilla Sixtina" de Berrocal es la serie de los Almogávares (1979-83)5. Yo creo que aquí en su obra máxima también se esconde su mayor disrupción y su mayor provocación bien escondida, y como siempre en infinitas direcciones.

Las formas sensuales de los temibles Almogávares es la disrupción total desde el punto de vista conceptual, los enviados por la Corona de Aragón tratados con su singular sensualidad. Añadir el elemento erótico en las formas hace enmudecer a cualquiera que se le cruce el tema sexual al estar viendo a los grandes guerreros que lograron retrasar sustancialmente la caída de Constantinopla a manos del imperio turco. Aquí se encuentra una de las sonrisas del genio, la otra gran sonrisa es que mover estas obras es de un tremendo esfuerzo logístico yo creo que esto es el regalo final de Berrocal hacia a los galeristas y museos. Como la respuesta a una pregunta retórica: Las piezas pequeñas y múltiples no son arte, ¿verdad?... Pues aquí tenéis un magnífico regalo, eso si, pesa un poco.

Cuando se mezclan elementos aparentemente tan alejados como la ingeniería y el erotismo. La disrupción que genera es tan grande que permite a Berrocal que nos ponga una venda sobre los ojos, que confiemos en él y le acompañemos guiados con cariño hacia nuevos mundos, como si fuéramos la protagonista de Historias de $\mathrm{O}$ en busca de nuevas experiencias.

Conversando y reflexionando con Cristina de Braganza sobre la poesía y el erotismo del trabajo de Berrocal, citó a modo de conclusión y de forma muy inteligente una frase de Jean Paul Sartre (1943) que sintetizaba de forma clara nuestro pequeño gran viaje conjunto:

"Le plaisir est la mort et l'échec du désir"

\footnotetext{
5 Opus 250 Roger de Flor / Almogávar I (1981-83), opus 251 Ramón Muntaner / Almogávar II (1981-83), opus 252 Bernardo de Rocafort / Almogávar III (1981-83), opus 253 Sancho de Oros / Almogávar IV (1981-83) opus 254 Roger de Lauria / Almogávar V (1981-83), opus 255 Berenguer de Entenza / Almogávar VI (1981-83), opus 256 Corbarán de Alet / Almogávar VII (1981-83), opus 257 Ximenes de Arenos / Almogávar VIII (1981-83), opus 258 Berenguer de Rondor / Almogávar IX (1981-83), opus 259 Guillén de Tous / Almogávar X (1981-83)

Umática. 2019; 2: 131-166
} 


\section{Referencias Bibliográficas / References}

Berrocal, M., Gállego, J., \& Pasoni, F. (1984). Antológica Berrocal (1955-1984): Palacio de Velázquez, Parque del Retiro, Madrid, octubre-diciembre 1984.Madrid: Dirección General de Bellas Artes y Archivos.

Berrocal, M., \& Institut Valencià d'Art Modern (2002). Berrocal. Valencia: IVAM Institut Valencià d'Art Modern.

Berrocal, M., Et Marchiori, G. (1973). La sculpture de Berrocal. Bruxelles: La Connaissance

Buñuel, Luis (1982). Mi último suspiro. [Trad. español: Ana María de la Fuente. Mon dernier soupir. París. Éditions Robert Laffont] Barcelona: Random House Mondadori.

Jarry, A. (2004). Gestas y opiniones del Doctor Faustroll, Patafísico [Trad. español: Víctor Goldstein. Gestes et opinions du Docteur Faustroll Payaphysicien. Paris. 1911] Buenos Aires, Argentina: Atuel.

Sartre, J.P. (1943). L'Etre et le Néant. Paris;

\section{Créditos:}

Fotógrafo: Emilio Schargorodsky

Curator: David López

Modelos: Lucía G. Lara, Nelliel, Domina

Ghalia, Necar, CPH, Gretchen y Tier

Dirección de fotografía: Quique Mañas

Edición de color y postproducción digital: Patricia Flores

Asistente de dirección y fotografías making of: Belén Landa

Maquillaje: Estefanía Villalba 